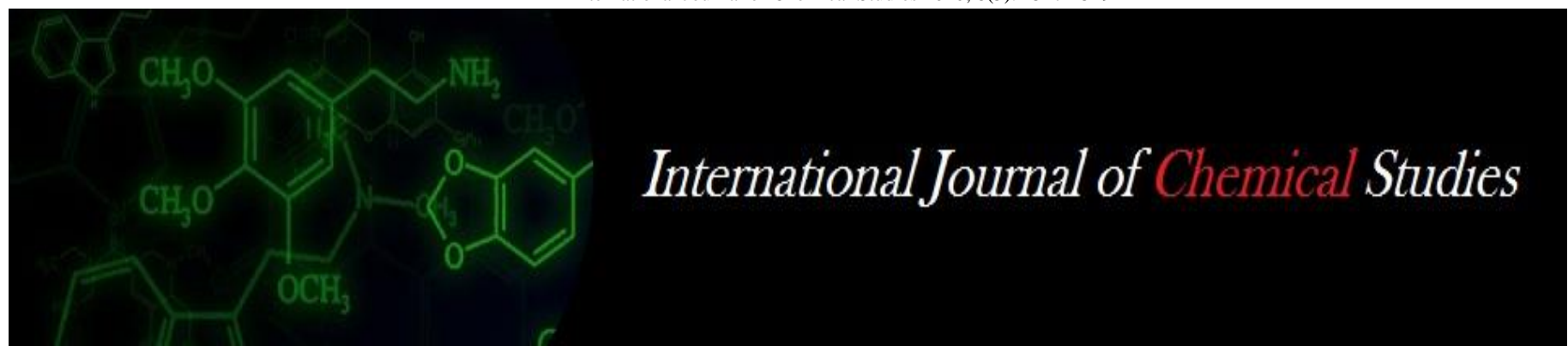

P-ISSN: 2349-8528

E-ISSN: 2321-4902

www.chemijournal.com

IJCS 2020; 8(5): 1517-1519

(C) 2020 IJCS

Received: 17-07-2020

Accepted: 26-08-2020

Sukalu Ram Netam

Department of Fruit Science,

College of Agriculture (IGKV)

Raipur, Chhattisgarh, India

\section{GD Sahu}

Department of Fruit Science, College of Agriculture (IGKV) Raipur, Chhattisgarh, India

\section{PS Markam}

College of Agriculture and Research Station (IGKV),

Kanker, Chhattisgarh, India

Asnath Prerna Minz Department of Fruit Science, College of Agriculture (IGKV) Raipur, Chhattisgarh, India

Corresponding Author: Sukalu Ram Netam Department of Fruit Science, College of Agriculture (IGKV) Raipur, Chhattisgarh, India

\section{Effect of different growing media on rooting and survival percentage of pomegranate (Punica granatum L.) cuttings cv. Super Bhagwa under Chhattisgarh plains condition}

\author{
Sukalu Ram Netam, GD Sahu, PS Markam and Asnath Prerna Minz
}

DOI: https://doi.org/10.22271/chemi.2020.v8.i5u.10514

\begin{abstract}
The present investigation was conducted at Research field of Department of Fruit Science College of Agriculture Raipur (C.G.) during 2019-20. Entitled "Studies on the effect of different growing media on rooting and shooting of pomegranate (Punica granatum L.) cuttings cv. Super Bhagwa under Chhattisgarh plains condition." The experiment was consisting different type of growing media and their combination viz. $\mathrm{T}_{0}$ - Garden soil (control), $\mathrm{T}_{1}$ - Sand, $\mathrm{T}_{2}$ - Vermicompost, $\mathrm{T}_{3}$ - Coco peat, $\mathrm{T}_{4}-\mathrm{Saw}$ dust, $\mathrm{T}_{5}$ FYM, T6- Poultry manure, T7- Sand + Vermicompost (1:1), T8- Sand + Cocopeat(1:1), T9- Sand + Saw dust (1:1), $\mathrm{T}_{10-}$ Sand $+\operatorname{FYM}(1: 1)$, and $\mathrm{T}_{11-}$ Sand + Poultry manure (1:1). To find out the influence of various type of media on rooting and survival percentage of pomegranate. The overall best performance was observed in media combination $\mathrm{T}_{8}$ for rooting and survival percentage. Number of roots per cutting (32.44), Length of roots $(30.37 \mathrm{~cm})$, Diameter of roots $(1.52 \mathrm{~mm})$, Fresh weight of root $(4.15 \mathrm{gm})$, Dry weight of root $(1.55 \mathrm{gm})$, Survival percentage $(80.61 \%)$. When used alone garden soil medium result showed the least performance and provide unsatisfactory result for rooting and survival parameter.
\end{abstract}

Keywords: Pomegranate cuttings, garden soil, sand, vermicompost, cocopeat, sawdust, FYM, poultry manure

\section{Introduction}

Pomegranate (Punica granatum L.) belonging to family Punicacece, is an ancient fruit originated in Persia, Afghanistan and Baluchistan (De Candolle, 1967) ${ }^{[3]}$ and is also thought to be indigenous to the region of Iran, but later spread to Mediterranean countries.

Pomegranate is the most popular fruit and cultivated in tropical and sub-tropical parts of the world. Spain and Iran are the leading producers of pomegranate. In India, it is cultivated in an area of about 234 thousand hectares and Production of about 2845 thousand MT (Annonymus, 2017-18) ${ }^{[2]}$.

Pomegranate is a small, deciduous plant propagated by sexual and asexual means. Rhizogenesis is the most frequently used organo genetic phenomenon in pomegranate (Punica granatum L.) vegetative multiplication. Vegetative propagation by cuttings is the most commercial, convenient and cheap method to get true to type plants. In order to reduce the high mortality of rooted cuttings under field conditions, it is highly desirable to build a healthy and well developed root system for enabling better field establishment of pomegranate trees through the use of suitable plant growth regulator treatment. Rooting ability depends on the genetic characteristics of a plant (De Klerk and Brugge, 1992) ${ }^{[4]}$, environmental conditions (Moe and Anderson 1988) ${ }^{[7]}$, and the exogenous and endogenous supply of biochemical constituents. Rooting media is one of the most important factors for better rooting of cutting and survival of plant. There are different media like soil, sand, perlite, vermiculite, FYM, etc. which play an important role in success of rooting of cutting. Some media have higher moisture holding capacity with lighter weight, which enhance root formation. So, rooting of cutting can be significantly increased with use of different media.

\section{Material Method}

The present investigation was conducted at Research field of Department of Fruit Science Collage of Agriculture Raipur (C.G.) during 2019-20. 
It consisted of 12 treatments combination mention below which were carried out in a completely randomized design (CRD) with three replications. And each replication 12 treatments, Total number of cutting per treatment 10, Total number of cutting 360 .

\section{Treatment details}

\begin{tabular}{|c|c|c|}
\hline S. No & Notation & Treatment Combinations \\
\hline 1 & $\mathrm{~T}_{0}$ & Garden soil (Control) \\
\hline 2 & $\mathrm{~T}_{1}$ & Sand \\
\hline 3 & $\mathrm{~T}_{2}$ & Vermicompost \\
\hline 4 & $\mathrm{~T}_{3}$ & Cocopeat \\
\hline 5 & $\mathrm{~T}_{4}$ & Sawdust \\
\hline 6 & $\mathrm{~T}_{5}$ & Farm Yard Manure \\
\hline 7 & $\mathrm{~T}_{6}$ & Poultry Manure \\
\hline 8 & $\mathrm{~T}_{7}$ & Sand + Vermicompost $(1: 1)$ \\
\hline 9 & $\mathrm{~T}_{8}$ & Sand + Cocopeat $(1: 1)$ \\
\hline 10 & $\mathrm{~T}_{9}$ & Sand + Sawdust $(1: 1)$ \\
\hline 11 & $\mathrm{~T}_{10}$ & Sand + FYM(1:1) \\
\hline 12 & $\mathrm{~T}_{11}$ & Sand + Poultry Manure $(1: 1)$ \\
\hline
\end{tabular}

\section{Result and Discussion}

The survival percentage and roots parameters of pomegranate can be defined as the percentage of survival of alive cutting pomegranate and number of roots per cutting, length of roots $(\mathrm{cm})$, diameter of roots $(\mathrm{mm})$, Fresh weight of roots $(\mathrm{gm})$, and dry weight of roots $(\mathrm{gm})$. It was recorded after 120 days of planting the cutting. Among the different growing media, significantly highest survival percentage of pomegranate was registered with treatment $\mathrm{T}_{8}$ - sand + cocopeat $(1: 1)(80.61 \%)$ in comparison to others growing media. However, it was at par to treatment $\mathrm{T}_{3}$ - cocopeat $(77.67 \%)$. The survival percentage of pomegranate was noted significantly lowest under treatment $\mathrm{T}_{0}-$ control $(47.24 \%)$. The increase in survival could be attributed to better water holding capacity and nutrient availability. This result is in close conformity with the earlier result given by Singh et al. $(2015)^{[6,11]}$ and Kumar et al. (2015) ${ }^{[6]}$ in guava.

The data related to number of roots per cutting as influenced by different growing media are presented in Table. 1 and reveals that number of roots per cutting of pomegranate was significantly affected by different growing media. Whereas, significantly maximum value of these parameter was noticed under treatment $\mathrm{T}_{8}$ - sand + cocopeat (1:1) (32.44) which was at par to treatment $\mathrm{T}_{3}$ - cocopeat (30.52). Significantly lowest number of roots per cuttings was recorded with treatment $\mathrm{T}_{0}-$ control (21.67). It might be due to release of sufficient nutrients and good aeration in the root zone of the cuttings. The present finding regarding numbers of roots are in consonance with the report of Singh et al. (2015) ${ }^{[6]}$ and Rymbai et al. (2008) ${ }^{[10]}$.

The data reveals that length of roots per cutting differed significantly affected by different growing media, where significantly highest value was recorded in the treatment $\mathrm{T}_{8}$ sand + cocopeat (1:1) (30.37) as compared to others growing media. However, it was at par to treatment $T_{3}-$ cocopeat (28.56). The lowest length of roots per cuttings was noted significantly under treatment $\mathrm{T}_{0}-$ control (23.00). This result is similar with the finding of Sweth (2005) who also reported that longer roots was obtained in cocopeat substance as a compared to soil in Indian lavender, similarly Singh et al. $(2015)^{[6,11]}$ and Kumar et al. (2015) ${ }^{[6]}$ and Rajkumar et al. (2017) ${ }^{[9]}$ also reported that the maximum root length was measured in perlite + cocopeat combination in the pomegranate cuttings.

Table 1: Effect of different growing media on survival percentage of cuttings, number of roots per cuttings, length of roots cuttings ${ }^{-1}$

\begin{tabular}{|c|c|c|c|c|}
\hline Notation & Treatments & Survival \% & No of roots cutting ${ }^{-1}$ & Length of roots cuttings $^{-1}(\mathrm{~cm})$ \\
\hline $\mathrm{T}_{0}$ & Garden soil (Control) & 47.24 & 21.67 & 23.00 \\
\hline $\mathrm{T}_{1}$ & Sand & 54.13 & 23.27 & 23.90 \\
\hline $\mathrm{T}_{2}$ & Vermicompost & 71.46 & 28.90 & 25.60 \\
\hline $\mathrm{T}_{3}$ & Cocopeat & 77.67 & 30.52 & 28.56 \\
\hline $\mathrm{T}_{4}$ & Sawdust & 49.23 & 21.93 & 23.60 \\
\hline $\mathrm{T}_{5}$ & Farm Yard Manure & 57.25 & 24.13 & 24.16 \\
\hline $\mathrm{T}_{6}$ & Poultry Manure & 62.23 & 28.13 & 25.16 \\
\hline $\mathrm{T}_{7}$ & Sand+Vermicompost $(1: 1)$ & 75.44 & 29.27 & 26.23 \\
\hline $\mathrm{T}_{8}$ & Sand + Cocopeat $(1: 1)$ & 80.61 & 32.44 & 30.37 \\
\hline $\mathrm{T}_{9}$ & Sand + Sawdust $(1: 1)$ & 51.13 & 22.60 & 23.63 \\
\hline $\mathrm{T}_{10}$ & Sand + FYM(1:1) & 58.23 & 25.97 & 24.90 \\
\hline $\mathrm{T}_{11}$ & Sand + Poultry Manure(1:1) & 67.41 & 28.33 & 25.46 \\
\hline SEm \pm & & 1.75 & 0.72 & 0.69 \\
\hline $\mathrm{CD}(\mathrm{P}=0.05)$ & & 5.10 & 2.09 & 2.00 \\
\hline
\end{tabular}

The data regarding diameter of roots per cutting of pomegranate as influenced by different growing media are presented in Table.2 Among the different growing media, significantly higher diameter of roots per cuttings of pomegranate was recorded in the treatment $\mathrm{T}_{8}$ - sand + cocopeat (1:1) (1.52) as compared to others growing media. However, it was at par to treatment $\mathrm{T}_{3}$ - cocopeat (1.46). The lower diameter of roots per cuttings of pomegranate was noted significantly under treatment $\mathrm{T}_{0}-$ control (1.08). This may be attributed to general improvement in the physical and chemical properties of the rooting medium which improved the growth of the roots and thus improve the diameter of roots. The similar results were obtained by Hasan et al. (2010) ${ }^{[5]}$ and Abirami et al. (2010) ${ }^{[1]}$.
The fresh weight of roots per cutting of pomegranate was significantly affected by different growing media. Among the different growing media, significantly maximum fresh weight of roots per cuttings of pomegranate was recorded in the treatment $\mathrm{T}_{8}$ - sand + cocopeat (1:1) (4.15) which was at par to treatment $T_{3}$ - cocopeat (3.95). The minimum fresh weight of roots per cuttings of pomegranate was observed under treatment $\mathrm{T}_{0}-$ control (2.68).

It may attribute due to fact of the supply of sufficient quantity of nutrients and good water holding capacity in the root zone of the cuttings of pomegranate (Ansari, 2013). Rajkumar et al. (2017) ${ }^{[9]}$ also noted maximum fresh root weight in Perlite + Cocopeat combination in pomegranate cuttings. 
The dry weight of roots per cuttings of pomegranate was significantly affected by different growing media. As regard to the different growing media, treatment $\mathrm{T}_{8}-$ sand + cocopeat (1:1) (1.55) recorded significantly maximum dry weight of roots $(\mathrm{g})$ per cutting in comparison to others growing media, which was at par to treatment $\mathrm{T}_{3}-$ cocopeat (1.47). The minimum dry weight of roots per cuttings of pomegranate was noted significantly in the treatment $\mathrm{T}_{0}$ - control (0.98). This might be attributed due to higher fresh weight of roots and ultimately led into higher dry weight of roots of cuttings. The result is in conformity with the findings of Patel et al. $(2012)^{[8]}$.

Table 2: Effect of different growing media on diameter of roots, Fresh weight of roots, Dry weight of roots

\begin{tabular}{|c|c|c|c|c|}
\hline Notation & Treatments & $\begin{array}{c}\text { Diameter of roots } \\
\text { cuttings }^{-1}(\mathbf{m m})\end{array}$ & $\begin{array}{c}\text { Fresh weight of roots } \\
\text { cuttings }^{-1}(\mathbf{g})\end{array}$ & $\begin{array}{c}\text { Dry weight of roots } \\
\text { cuttings }^{-1}(\mathbf{g})\end{array}$ \\
\hline $\mathrm{T}_{0}$ & Garden soil (Control) & 1.08 & 2.68 & 0.98 \\
\hline $\mathrm{T}_{1}$ & Sand & 1.22 & 3.25 & 1.15 \\
\hline $\mathrm{T}_{2}$ & Vermicompost & 1.36 & 3.85 & 1.31 \\
\hline $\mathrm{T}_{3}$ & Cocopeat & 1.46 & 3.95 & 1.47 \\
\hline $\mathrm{T}_{4}$ & Sawdust & 1.20 & 2.94 & 1.09 \\
\hline $\mathrm{T}_{5}$ & Farm Yard Manure & 1.31 & 3.49 & 1.17 \\
\hline $\mathrm{T}_{6}$ & Poultry Manure & 1.33 & 3.77 & 1.26 \\
\hline $\mathrm{T}_{7}$ & Sand+Vermicompost $(1: 1)$ & 1.40 & 3.89 & 1.35 \\
\hline $\mathrm{T}_{8}$ & Sand + Cocopeat $(1: 1)$ & 1.52 & 4.15 & 1.11 \\
\hline $\mathrm{T}_{9}$ & Sand + Sawdust $(1: 1)$ & 1.21 & 2.95 & 1.25 \\
\hline $\mathrm{T}_{10}$ & Sand + FYM(1:1) & 1.32 & 3.75 & 1.29 \\
\hline $\mathrm{T}_{11}$ & Sand+Poultry Manure(1:1) & 1.34 & 3.81 & 0.04 \\
\hline $\mathrm{SEm} \pm$ & & 0.03 & 0.08 & 0.11 \\
\hline $\mathrm{CD}(\mathrm{P}=0.05)$ & & 0.09 & 0.24 & \\
\hline
\end{tabular}

\section{Conclusion}

On the basis of experimentation on "Effect of different growing media on rooting and survival percentage of pomegranate (Punica granatum L.) cuttings cv. Super Bhagwa Under Chhattisgarh plains condition. Sand + Cocopeat (1:1) registered significantly higher survival percentage of pomegranate cv. Super Bhagwa hardwood stem cuttings was recorded. Significantly higher root growth (number of roots per cuttings, length of roots per cuttings, diameter of roots per cuttings, fresh weight of roots per cuttings and dry weight of roots per cuttings) were recorded under sand + cocopeat $(1: 1)$ in comparison to others growing medias. Since, it was the first year of experimentation it is suggested that the experiment should be continued for another year before making any definite recommendation.

\section{References}

1. Abirami K, Rema PA, Mathew. Effect of different propagation media on seed germination, seedling growth and vigour of nutmeg. Journal of Medicinal plants Research. 2010; 4(19):2054-2058.

2. Anonymous. Horticulture Statistics, National Horticulture Board, New Delhi, 2017. www.nhb.gov.in.

3. De Candolle A. Orgin of Cultivated Plants. Hafner Publication, Co. New York and London Distribution Co, Lucknow (UP), 1967, 237-240.

4. De Klerk GJ, Brugge J. Factors affecting adventitious root formation in microcuttings of Malus. Agron. 1992; 12:747-755.

5. Hasan MA, Manna M, Suresh CP. Standardization of growing media for seed germination in papaya. Abstract, 2010, 7-28 Final-KrishiBangla.com. 11.

6. Kumar V, Singh MK, Kumar M, Parkash S, Kumar A, Rao S. Effect of different dose of IBA and rooting media on rooting of stem cutting of lemon (Citrus lemon burm) cv. Pant Lemon-1. Journal of Plant Development Science. 2015; 7(7):587-591.

7. Moe R, Anderson AS. Stock plant environmental and subsequent adventitious rooting. In: Adventitious root formation cuttings (Eds. Davis TD, Haissig BE, Sankhla AN). Dioscorides Press, Portland, 1988, 214-234.
8. Patel DM, Nehete DS, Jadhav RG, Satodiya BN. Effect of PGRS and rooting media on air layering of different pomegranate (Punica granatum L.) cultivars. The Asian $\mathbf{J}$ Hort. 2012; 7(1):89-93.

9. Rajkumar R, Gora JS, Kumar R, Singh A, Kumar A, Gajender G. Effect of different growing media on the rooting of pomegranate (Punica granatum L.) cv.'Phule Arakta' cuttings. Journal of Applied and Natural Science. 2017; 9(2):715-719.

10. Rymbai H, Sathyanarayana SR, Reddy KCS. Effect of cocopeat and sphagnum moss on guava air layers and plantlets survival under open and polyhouse nursery. Agric. Sci. Digest. 2008; 32(3):241-243.

11. Singh VP, Mishra DS, Mishra NK, Rai R. Effect of growing season, PGR and rooting media on survival of hard wood stem cuttings of lemon (Citrus limon burm.) cv. Pant lemon-1. Hort Flora Research Spectrum. 2015; 4(4):347-350. 